\title{
High Altitude Illness
}

\author{
PR Davis, KTS Pattinson, NP Mason, P Richards, D Hillebrandt
}

Lt Col PR Davis RAMC

Consultant in

Emergency Medicine,

Southern General

Hospital, Glasgow

G51 4TF

Email:

peter.davis@sgh.scot.nhs.uk

\section{Dr KTS Pattinson}

Clinical Lecturer in

Anaesthesia

Nuffield Department of

Anaesthetics, University of Oxford,

John Radcliffe Hospital, Oxford OX3 9DU

Email: kyletsp@postmaster.co.uk

Dr NP Mason

Department of Critical

Care Medicine,

University Hospital of

Wales, Cardiff

CF14 4XW

\section{Dr P Richards}

General Practitioner,

The Surgery,

64 London Road,

Wickford, Essex

SS12 OAN

Director Medical

Expeditions

Email: paul@medex.org.uk

Dr D Hillebrandt

General Practitioner,

The Medical Centre,

Dobles Lane,

Holsworthy, Devon

EX22 6JX

Email: dh@hillebrandt.org.uk

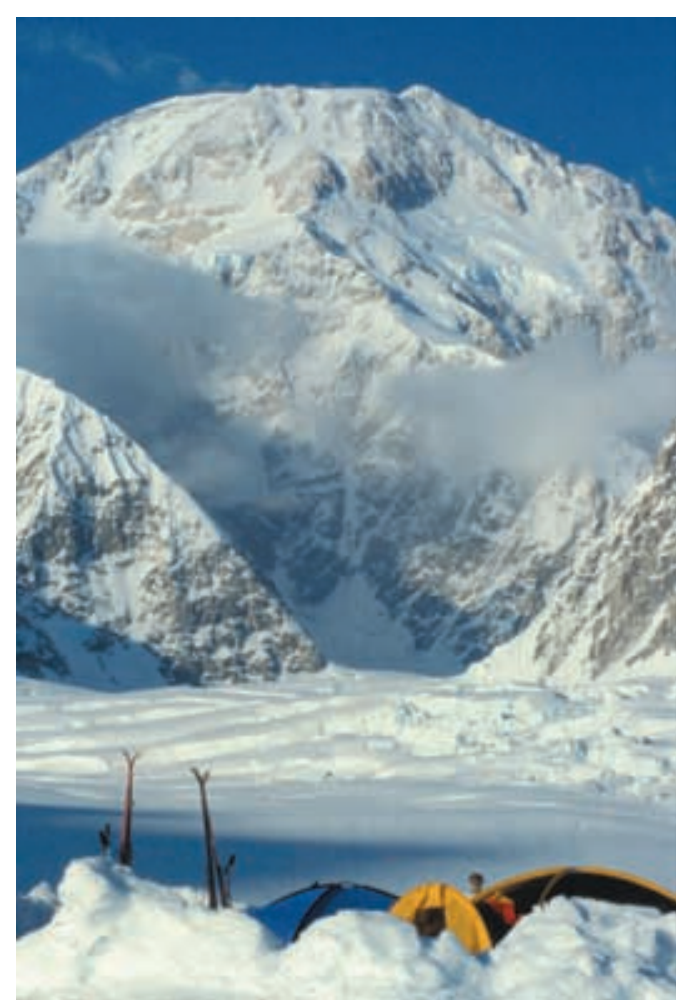

\section{Introduction}

The aims of this article are to outline the physiology of high altitude, the treatment of altitude illness and to describe opportunities for further education in mountain medicine.

Human difficulty with the rarefied air at high altitudes has been recognised since ancient times. Writings attributable to Aristotle (384-322 BC) describe travel on Mount Olympus in Macedonia: 'Also, because the rarity of the air which was there did not fill them with breath, they were not able to survive there unless they applied moist sponges to their noses' (1).

International frontiers frequently follow geographic features such as mountain ranges. This means that conflicts may well arise in high altitude areas (the European Alps of France and Italy in the Second World War, the Himalayan regions of India and Pakistan, and more recently the highlands of Afghanistan) with major implications for troop movement.

Definition of High Altitude

\begin{tabular}{|lr|}
\hline High altitude & $2500-3500 \mathrm{~m}$ \\
\hline Very High altitude & $3500-5800 \mathrm{~m}$ \\
\hline Extremely High altitude & beyond $5800 \mathrm{~m}$ \\
\hline
\end{tabular}

\section{Physiology of Altitude}

Sudden exposure of an unacclimatised individual to an altitude above $6000 \mathrm{~m}$ will result in loss of consciousness within 10 minutes. That mountaineers can remain conscious at these altitudes and reach the summit of Mount Everest at $8848 \mathrm{~m}$ without the use of supplementary oxygen bears witness to the remarkable adaptive changes that take place with acclimatisation to hypobaric hypoxia at extreme altitude. Acclimatisation is the process by which people adjust to altitude hypoxia. The body makes a series of adjustments, which increase the delivery of the available oxygen to cells, and increase the efficiency by which that oxygen is used. The most important component of acclimatisation is an increased rate and depth of breathing and this occurs relatively rapidly. Changes in bicarbonate concentration, haematocrit and haemoglobin occur over days to months.

Hyperventilation. Immediately on exposure to hypoxia the peripheral chemoreceptor in the carotid bodies stimulates the respiratory centres in the brainstem to increase ventilation. This hyperventilation causes a respiratory alkalosis, which initially limits the increase in ventilation by reducing the respiratory drive from the central chemoreceptor. Over the next few days however, the cerebrospinal fluid $\mathrm{pH}$ is normalised by a mechanism which is, as yet, not fully understood. The brake to ventilation is removed allowing further hyperventilation and ongoing defence of arterial $\mathrm{PO}_{2}$.

Renal function and fluid balance. Rapidly after arrival at altitudes above $3500-4000 \mathrm{~m}$ plasma volume is reduced by about $5 \%$ and this deficit would appear to persist for up to 4 months. Total body water is also reduced by around 5\% probably due to a combination of decreased water intake; changes in thirst regulation; increased insensible losses and an inappropriately unchanged urine output. Sodium and potassium balance seem to be unchanged. Acute mountain sickness (AMS) is associated with an anti-diuresis and fluid retention which is partly responsible for the characteristic sign of peripheral oedema seen in this condition.

Haematological changes. The rapid reduction in plasma volume results in an increase in haemoglobin concentration whilst at the same time hypoxia stimulates renal and 
hepatic erythropoietin production resulting in erythropoiesis and an increase in red cell mass.

Cardiovascular changes. It is possible to think of the purpose of acclimatisation as maintaining as near normal an oxygen delivery to the tissues as possible. Central to this is the cardiovascular system. Acute exposure to high altitude results in an increase in heart rate and cardiac output both at rest and for a given amount of work compared to sea level. With acclimatisation heart rate and cardiac output return towards their sea level values at rest up to altitudes of approximately $4500 \mathrm{~m}$. Above this altitude resting heart rate tends to be higher than resting at sealevel rate. During exercise, for a given level of work, heart rate still remains elevated compared to sea level although cardiac output returns to sea level values. Thus stroke volume must be reduced despite myocardial contractility being well preserved. In general the normal heart tolerates even severe hypoxia very well. Cardiac arrhythmias are rare at high altitude and even at extreme altitude the ECG shows only the changes of pulmonary hypertension. The increase in haemoglobin concentration which occurs as a result of plasma volume contraction and increased erythropoiesis has the effect of increasing the arterial oxygen content of the blood. Thus a well-acclimatised individual at altitudes up to $5500 \mathrm{~m}$ will have a similar arterial oxygen content and therefore oxygen delivery as at sea level.

Oxygen Consumption and Exercise. Maximal work, or oxygen consumption $\left(\mathrm{VO}_{2} \mathrm{max}\right)$, decreases with increasing altitude. Up to $6000 \mathrm{~m}$ a mountaineer chooses to function at between 50 and $75 \%$ of their $\mathrm{VO}_{2}$ max, but as altitude increases so the effort required for even simple physical tasks moves closer towards $\mathrm{VO}_{2}$ max. On the summit of Mount Everest the $\mathrm{VO}_{2}$ max is around 1.2 litres per minute, a work rate corresponding to walking slowly on the flat.

\section{Acute Mountain Sickness (AMS)}

AMS is defined by the Lake Louise consensus criteria (2) as the presence of a headache and at least one of the following symptoms after a recent increase in altitude: loss of appetite, nausea, vomiting, fatigue, weakness, dizziness, light-headedness or sleep disturbance. Typically the sleep disturbances include difficulty in onset of sleep, frequent wakening and periodic breathing. Headache is throbbing, worse at night and early in the morning. Classically the AMS sufferer has a headache, is off his or her food, and has difficulty sleeping. Rapid ascent to altitudes above $2500 \mathrm{~m}$ will frequently cause AMS. There are no pathognomic clinical signs in AMS, but symptoms appear $6-12$ hours after ascent, and usually resolve within three days if further ascent does not occur.

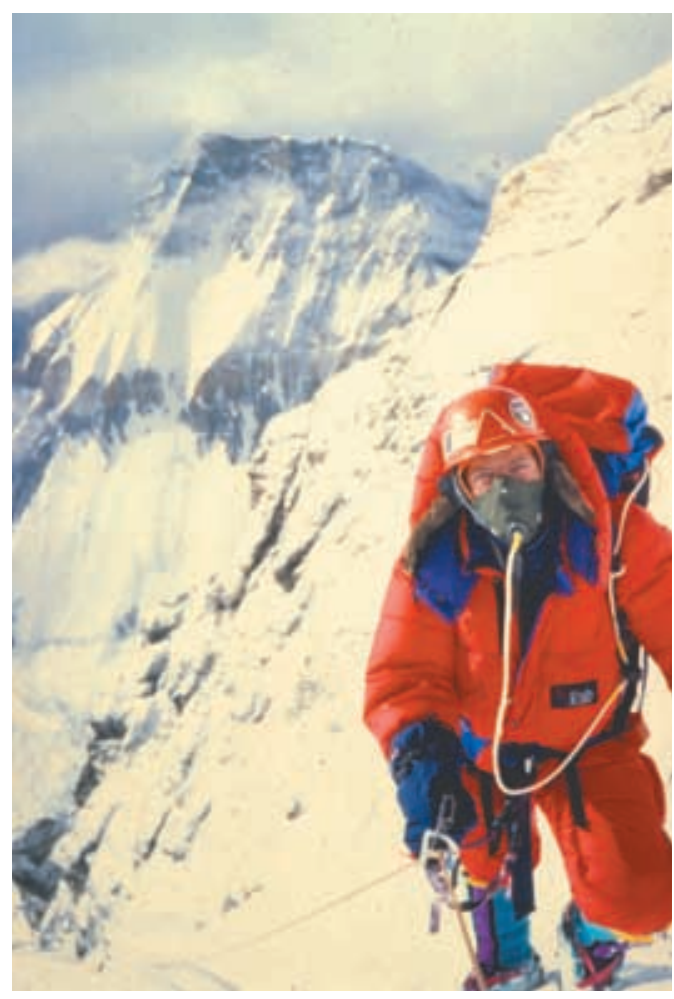

AMS Treatment. AMS is a mild altitude illness and is more of a nuisance in that it delays progression towards the objective of the expedition. The major concern in identifying AMS is that it might progress to life threatening high altitude cerebral oedema (HACE) or high altitude pulmonary oedema (HAPE).

Principles of treatment (summarised in Figure 1)

- Stop further ascent

- Descend if there is no improvement or if the condition worsens. $500-1000$ metres of descent is usually sufficient to rapidly reverse the symptoms of AMS.

- Descend immediately if there are symptoms or signs of cerebral or pulmonary oedema

When symptoms are mild, rest alone is often sufficient for symptoms to resolve. Aspirin, ibuprofen or paracetamol may relieve headache and antiemetics may be useful for symptomatic relief.

If symptoms are severe then the subject must descend to a lower altitude. If descent is not practical (due to position or clinical situation) then the following treatments may be beneficial: oxygen given by Hudson type mask at $1-2$ litres per minute or simulated descent in a portable hyperbaric chamber (PHC) will relieve symptoms when descent is impossible due to weather or terrain constraints. The use of the portable hyperbaric chamber (PHC) is described in more detail later in this article. Drug therapy may improve symptoms, allowing a patient to walk out rather than be carried. Oral acetazolamide at $250 \mathrm{mg}$ twice or three times daily and dexamethasone (4 mg four times daily, orally or intramuscularly) are both appropriate. The patient with AMS should never be 
left alone as the condition may progress to HACE or HAPE, and descent should be to an altitude lower than that where the symptoms began.

\section{High Altitude Cerebral Oedema (HACE)}

HACE is rare but life threatening $(1-2 \%$ of those who ascend rapidly to $4500 \mathrm{~m}$ ) (3). HACE and AMS are thought to be opposite ends of the same disease spectrum, and AMS usually precedes HACE. It is unusual below $3500 \mathrm{~m}$, but has occurred as low as $2500 \mathrm{~m}$. When death occurs it is due to brainstem herniation.

\section{Signs and symptoms}

HACE is characterised by ataxia and altered consciousness. The classic HACE victim progresses from AMS to become confused, disorientated, irrational, and ataxic. The victim then begins to hallucinate. Lethargy progresses to coma, and death follows rapidly if emergency treatment is not commenced. Even when treated successfully, it should be noted that ataxia may persist for some days afterwards before the person returns entirely to normal and cases with residual neurological deficit have been reported. These may be cases of "non HACE neurological problems of altitude".

High altitude pulmonary oedema (HAPE) may occur concurrently with HACE, and should be treated if present.

\section{HACE Treatment}

Descent is imperative. Although exhaustion, dehydration, hypothermia, alcohol hangover or migraine may mimic AMS and HACE, any suspicion of HACE mandates immediate descent (4). Heel-toe walking in a straight line is a simple tool to gauge ataxia. The Sharpened Romberg Test has also been shown to reliably demonstrate ataxia in the field as part of a clinical examination (5). Dexamethasone should be given intramuscularly, intravenously, or orally if the patient is not vomiting. The initial dose is $8 \mathrm{mg}$ followed by $4 \mathrm{mg}$ six-hourly. This will provide symptomatic relief in order to facilitate descent; it does not treat the underlying cause of the condition (hypoxia). When descent cannot proceed immediately either due to weather, terrain or other safety constraints, or due to the condition of the patient, then oxygen and drugs must be administered regularly and prolonged hyperbaric treatment must continue. Once the patient has been successfully treated and evacuated to a lower altitude, review by a medical practitioner as early as possible is mandatory.

\section{High Altitude Pulmonary Oedema (HAPE)}

HAPE is usually provoked by very rapid ascent to high altitude. In one study, $10 \%$ of climbers ascending very rapidly (e.g. by helicopter) to $4500 \mathrm{~m}$ developed HAPE (6). With usual ascent profiles only $1-2 \%$ of climbers would be expected to develop HAPE in ascending to the same altitude. It is concerning that climbers at extreme high altitude on occasion develop HAPE, the common situation being that they have acclimatised to around $5500 \mathrm{~m}$, but then develop HAPE during a rapid ascent to $7000 \mathrm{~m}$ or more.

Signs and symptoms. HAPE may be preceded by AMS, but may occur in isolation. Exertional dyspnoea and reduced exercise tolerance occur, which are worse than that expected for the altitude or worse than that of the victim's expedition peers. This progresses to disproportionate dyspnoea and tachypnoea at rest, worse at night. Early symptoms of HAPE include an annoying dry cough, which may be indistinguishable from the usual cough experienced at high altitude. As the condition progresses, the cough becomes bubbly and wet with sputum which may be bloodstained. Tachycardia and tachypnoea occur at rest and it is possible to hear crackles in the lung fields with a stethoscope. There may be a mild fever (commonly less than $38.5^{\circ} \mathrm{C}$ ), and for this reason it may be difficult to differentiate HAPE from pneumonia. The measurement of arterial oxygen saturation $\left(\mathrm{SpO}_{2}\right)$ in itself will not confirm a diagnosis of HAPE, but $\mathrm{SpO}_{2}$ can be used to mark the progression of the condition once treatment has commenced (7). A fingertip probe such as the Nonin Onyx ${ }^{\mathrm{TM}}$ (Nonin Medical Inc., 13700 1st Avenue North, Plymouth, Minnesota, USA) is compact and ideal.

\section{Treatment of HAPE}

Oxygen must be given immediately if available, and descent commenced (8). Ideally, oxygen should be titrated until $\mathrm{SpO}_{2}$ reaches $90 \%$, but care must be taken in conserving oxygen supplies for the expected duration of treatment, prior to evacuation (9). Exertion and cold exacerbate HAPE through an increased sympathetic drive causing further pulmonary vasoconstriction. The patient should ideally be carried in a sitting position and kept warm. Nifedipine should be given by mouth in the dosage of $20 \mathrm{mg}$ four times daily. It has previously been suggested that an initial $10 \mathrm{mg}$ dose should be administered sublingually. This is now not recommended due to the risk of hypotension and a fall in cardiac output. Additionally where HACE co-exists with HAPE, nifedipine-induced hypotension may reduce cerebral perfusion and cause further abnormal neurological function. If immediate evacuation is impossible, then similar considerations as described for HACE should be observed. 
UNIVERSAL ALTITUDE ILLNESS TREATMENT ALGORITHM

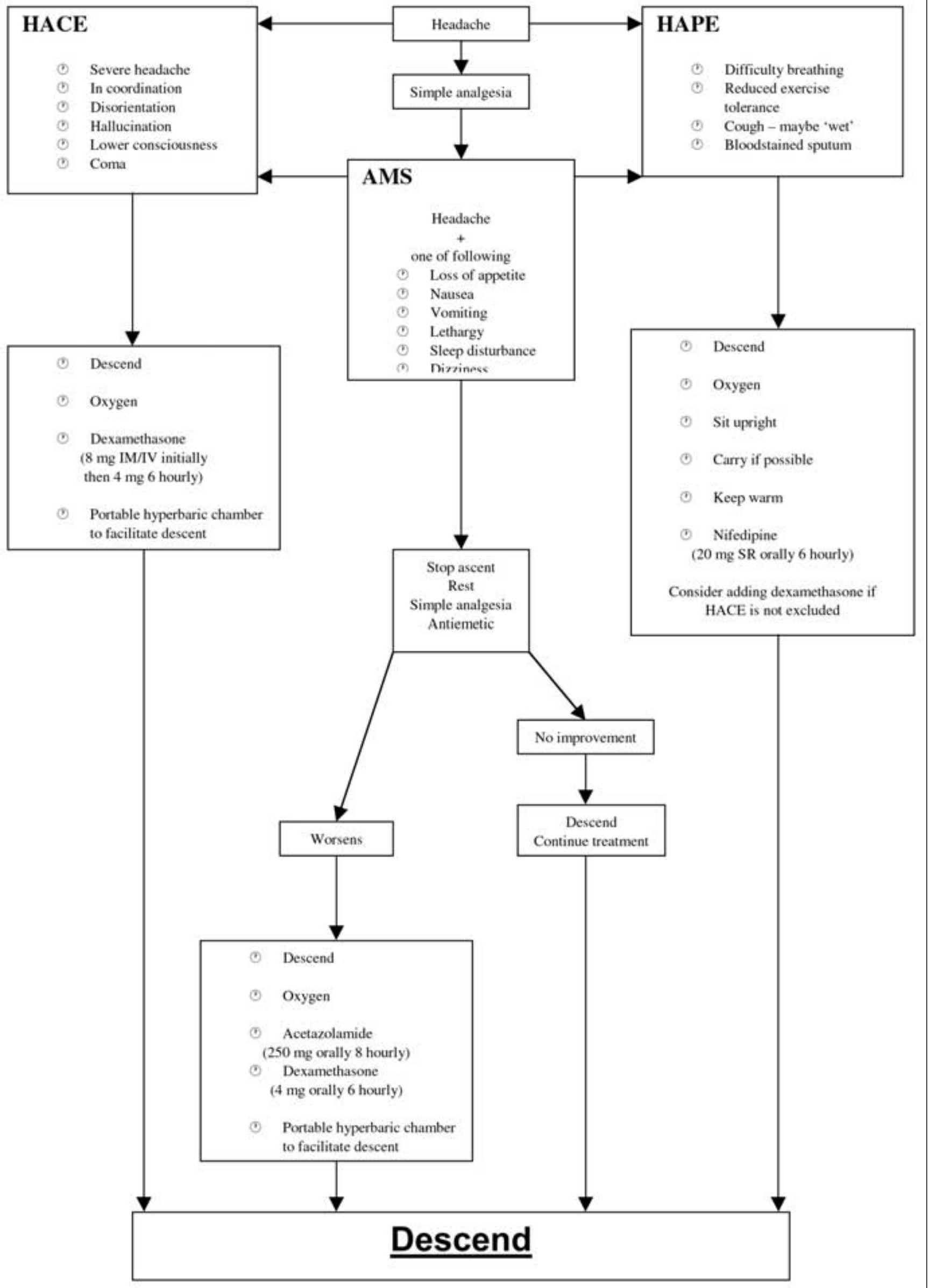




\section{Hyperbaric Therapy and The Portable Hyperbaric Chamber (PHC)}

Portable Hyperbaric Chambers have been in use since the late 1980s (10). Currently there are three models available: the Gamow bag, the CERTEC bag and the Portable Altitude Chamber (PAC). The apparatus consist of a conical or cylindrical fabric bag that is capable of being pressurised by a hand or foot driven pump. The patient is placed inside the bag lying flat. Each kit is lightweight and robust and weighs around $7 \mathrm{~kg}$ in total. The patient is zipped within the bag and pump strokes are made continuously to maintain the internal pressure at between 105 and 165 $\mathrm{mmHg}$ depending upon the model of bag. The air around the patient is thus pressurised. In this way the PHC simulates descent. Used correctly at $6000 \mathrm{~m}$, the apparent altitude

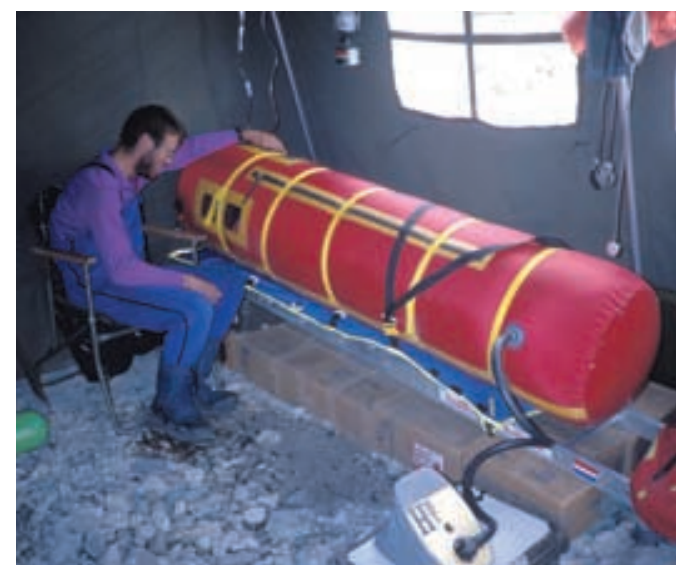

within the bag can be reduced to between 3500 and $3000 \mathrm{~m}$. Because of this, dramatic improvement can be produced in a patient with AMS, HACE or HAPE. Care must be taken if the patient is vomiting and, therefore, at risk if in an enclosed bag. Instruction must be given in ear decompression by valsalva. It can be useful for the patient to take an altimeter into the chamber with them and to hold it up to the window to indicate the virtual descent that has been achieved. Patients with HAPE may not tolerate the supine position and so the whole bag may need to be inclined to alleviate their distress. This can be improvised in the field using articles of camp equipment. One to two hours treatment is required to cause sufficient clinical improvement for a patient to be able to descend more easily. The benefit is short-lived outside of the bag, and will last no longer than 10 hours. When descent is not possible the hyperbaric therapy should be repeated at intervals of no less than five hours (8). Irrespective of the benefit from hyperbaric therapy, any patient who has been sick enough to require this form of treatment must descend as soon as practicable to an altitude below which the symptoms first began, and re-ascent must only take place after consultation with a medical practitioner familiar with altitude medicine.

\section{Prevention of altitude illness}

The key to the prevention of altitude illness is to allow acclimatisation to proceed. The adoption of a safe ascent profile is essential. Some people acclimatise rapidly, whilst others develop acute mountain sickness and require longer periods of time to fully acclimatise. If someone has been a slow acclimatiser on one journey, then it should be expected that the same pattern would repeat on subsequent trips. It is therefore important to allow party members to acclimatise at their own pace. Successful acclimatisation has occurred when the symptoms of AMS disappear, and sleep becomes more settled. Further ascent to a higher altitude will require further acclimatisation, and on descent to low altitude the beneficial effects will last no longer than about eight days. Rapid ascent to high altitudes should be avoided. If absolutely necessary, exercise should be kept to an absolute minimum on the subsequent days after arrival at altitude. The optimum is a graded ascent. Above $3000 \mathrm{~m}$, sleeping altitude should be sited at an elevation no more than $300 \mathrm{~m}$ above that of the previous night. A rest day should be taken after every third day or after each successive $1000 \mathrm{~m}$ of overall ascent. Further ascent should not proceed in individuals who are experiencing symptoms of AMS. These individuals must be supervised by a companion, and not left alone. Descent must be considered as life threatening altitude illness may supervene (HACE, HAPE).

\section{Chemoprophylaxis}

The use of prophylactic medication should only be considered in the following circumstances:

1. When the ascent profile is likely to provoke altitude illness through forced rapid ascent, e.g. flying or driving to high altitude due to time or logistical constraints, or when a rescue mission is initiated and personnel have to move rapidly to high altitude.

2. In those personnel who have a proven susceptibility to AMS or HAPE through previous exposure to high altitude.

Acetazolamide is the preferred agent. The standard regime is $250 \mathrm{mg}$ twice daily, commencing 24 hours prior to ascent (9). Other regimes are quoted, but maximal efficacy will be achieved with this regime. Dexamethasone may used as an alternative, or given in conjunction with acetazolamide in the dose of 4 mg twice daily though use is moderated by concerns for the usual side effects of potent steroids.

\section{Activity at Extreme Altitudes}

Adults can fully acclimatise to about 5000 $5800 \mathrm{~m}$. Above this there is a trade off between adjustment to altitude and deterioration due to prolonged hypoxia. Above 
$8000 \mathrm{~m}$, no acclimatisation occurs at all and a prolonged stay at that altitude is incompatible with life. Despite being fully acclimatised, prolonged exposure to heights above $7000 \mathrm{~m}$ in excess of $3-4$ days should be avoided as the physical and psychological stress becomes greatly exacerbated. Typical features include progressive weight loss, worsening appetite, poor sleep and increasing apathy. Minor ailments such as a viral sore throat or chest infection, that would simply be inconvenient at lower elevations, become more significant at extreme altitude and contribute to the overall malaise of the individual. For those expeditions going to extreme altitude, the base camp should be sited at or below $5000 \mathrm{~m}$ when possible, so that proper recovery can take place between sorties to higher elevations.

\section{Altitude Medicine}

In both Mountain Medicine and Military Medicine the environment frequently dictates the management of the patient. This requires a doctor who is capable of working without immediate support from colleagues and who can adapt protocols to the conditions and terrain encountered.

To work in any extreme environment the first essential is to be confident in that environment. The best training for mountain medicine is to climb, climb, and climb. One needs to build up experience in all aspects of the sport in summer and winter, by day and night, at all altitudes from sea cliffs to high mountains.

Most expedition medical problems are, in fact, minor and involve a large psychological element and, therefore, experience in general practice is extremely useful. Emergency Medicine and Critical Care are disciplines that will develop confidence and practice in managing traumatic injury and life threatening illness, as well as minor injuries and ailments. Pre-Hospital Care experience makes one aware of environmental risks ( 11).

Professional organisations relevant to mountain medicine are: The British Association for Immediate Care (BASICS) (12) , the British Travel Health Association (BTHA) (13), The International Society for Mountain Medicine (ISMM) (14) with its journal "High Altitude Medicine and Biology", and the USA based Wilderness Medicine Society (WMS) (15) also with its journal "Wilderness and Environmental Medicine"

The Diploma of Mountain Medicine is coordinated at an international level by the Union Internationale des Associations d'Alpinisme Medical Commission (UIAA Medcom). Currently about 2000 doctors hold this worldwide, and in the UK it is administered by Medical Expeditions $(16,17)$. It is no coincidence that fifty percent of the syllabus involves mountain skills (18) but there is increasing academic input via national univer- sities with rigorous academic assessment as well as mountain skill assessment $(18,19,20)$. The UIAA Diploma is currently running in France, Spain, Switzerland, Italy, Austria, Germany and the Netherlands (21). In the USA the WMS runs relevant courses and some universities are setting up programmes (22).

It is neither possible, nor desirable, to have doctors available in all remote areas so high quality training is needed for lay mountaineers (23). These climbers need to understand the principles of altitude and remote area medicine and to be competent to administer life saving medication to buy time for descent.

\section{Further Reading}

Pollard AJ, Murdoch DR. The High Altitude Medicine Handbook. Oxford: Radcliffe Medical Press; 2003.

Ward MP, Milledge JS \& West JB. High Altitude Medicine And Physiology. 3rd Ed. London: Arnold; 2000.

Barry PW, Pollard AJ. Altitude Illness. BMJ 2003; 326(7395): 915-19.

\section{References}

1. West J. High Life. A History of High Altitude Physiology and Medicine. Oxford University Press; 1998.

2. Roach RC, Bärtsch P, Oelz O, Hackett PH, Lake Louise AMS Scoring Consensus Committee. The Lake Louise acute mountain sickness scoring system. In: Sutton JR, Houston CS, Coates G, eds. Hypoxia and molecular medicine. Burlington Vt.: Charles S. Houston; 1993.

3. Hackett PH, Roach RC. High Altitude Cerebral Oedema. High Alt Med Biol 2004;5(2):136-46.

4. Basnyat B, Cumbo TA, Edelman R. Acute medical problems in the Himalayas outside the setting of altitude sickness. High Alt Med Biol 2000;1:167-74.

5. Johnson MB, Wright AD, Beazley MF et al. The Sharpened Romberg Test for assessing ataxia in mild acute mountain sickness. Wilderness Environl Med 2005;16:62-66.

6. Bartsch P, Maggiorini M, Ritter $M$ et al. Prevention of high altitude pulmonary oedema by Nifedipine. $N$ Engl F Med 1990;325:1284-89.

7. Roach RC, Greene ER, Schoene RB et al. Arterial oxygen saturation for prediction of acute mountain sickness. Aviat Space Environ Med 1998;69(12): 1182-85.

8. Pollard AJ, Murdoch DR. High Altitude Illness. In: The High Altitude Medicine Handbook. Oxford: Radcliffe Medical Press; 2003.

9. Hackett PH, Roach RC. High-altitude illness. N Engl f Med 2001;345:107-14.

10. Dubois C, Herry JP and Kayser B. Portable hyperbaric medicine, some history. $\mathcal{f}$ Wilderness Med 1994;5:190-8.

11. Peters P. Personal and professional profile of mountain medicine physicians. Wilderness Environl Med 2003;14(3):155-160.

12. http://www.basics.org.uk

13. http://www.btha.org

14. http://www.ismm.org

15. http://www.wms.org

16. http://www.medex.org.uk

17. Brookes MJ, Richards P. The Diploma in Mountain Medicine. F R Army Med Corps 2004;150(4):28790.

18. Peters P. Mountaineering and climbing techniques in the curriculum of mountain medicine education programs: a survey of the European Courses for Mountain Medicine. Wilderness Environl Med 2002;13(1):59-65. 
19. Peters P. Practical aspects in mountain medicine. Wilderness Environl Med 2000;11(4):262-68.

20. K Pattinson. S Matthews. Climbing the educational mountain: designing the new Diploma in Mountain Medicine in the United Kingdom. Wilderness Environl Med 2004;15(1):44-49.

21. Peters P. Plotz W. Mountain medicine education in Europe. Wilderness Environl Med 1998;9(1):19-27.

22. Macias DJ, Rogers K, Alcock J. Development of a wilderness and travel medicine rotation in an academic setting. Wilderness Environl Med 2004; 15(2):136-145.
23. Hillebrandt D. Medical educational needs of British Mountain Guides operating internationally. Pre-hosp Immed Care 2000;4:76-79.

\section{Conflict of Interest}

All authors are Faculty of the UK UIAA/IKAR/ISMM

Diploma of Mountain Medicine. DH and PR undertake part time work as medical advisors to a Commercial Expedition Company (Jagged Globe). 